\title{
Effects of Community-Based Interventions in Reducing the Obesity and Overweight Rate Among Iranian Women: Using Urban Health Equity Assessment and Response Tool
}

\author{
Farzaneh Rassam', Leila Khedmat², Farnaz Khatami ${ }^{*}$ \\ ${ }^{1}$ Health Department, The Tehran Municipality's Organization, 15th District, Tehran, Iran \\ ${ }^{2}$ Health Management Research Center, Baqiyatallah University of Medical Sciences, Tehran, Iran \\ ${ }^{3}$ Department of Community Medicine, School of Medicine, Tehran University of Medical Sciences, Tehran, Iran
}

Corresponding Author: Farnaz Khatami, MD, Assistant Professor, Department of Community Medicine, School of Medicine, Tehran University of Medical Sciences, Tehran, Iran. Tel: +98-21-64053218, Email: f-khatami@sina.tums.ac.ir

Received May 12, 2019; Accepted September 6, 2019; Online Published September 20, 2019

\begin{abstract}
Introduction: The increasing prevalence of overweight and obesity is one of the most critical issues of urban health. The current study investigated the effects of community-based interventions on modification of overweight and obesity.

Methods: A program based on the Urban Health Equity Assessment and Response Tool (Urban HEART) was developed and implemented in 2013-2014. A total of 166 Iranian females aged 15 years or older who were classified as overweight or obese using body mass index (BMI) were randomly selected and gave verbal consent to participate in this study. The intervention was carried out for a duration of 4 months.

Results: The mean age of subjects was $43.6 \pm 12.2$ years. The total number of overweight and obese individuals were $75(45.2 \%)$ and 91 (54.8\%), respectively. The mean BMI of the patients before and after the intervention was $30.3 \pm 2.7$ and $29.4 \pm 2.7 \mathrm{~kg} / \mathrm{m}^{2}$, respectively $(P<$ 0.05). Higher education level and greater floor area were recognized as valid predictors for reduced BMl after the intervention $(P<0.001)$. Conclusion: This study successfully represents the collaborative role of the community in improving health status by reducing overweight and obesity. The Urban HEART provided distinct opportunities for presenting the promising results of interventions to health policymakers and managers so they can adjust macro and micro policies for achieving better community health outcomes.

Keywords: Overweight, Obesity, Public Health, Preventive Medicine, Disease, Health Status
\end{abstract}

Citation: T. Effects of community-based interventions in reducing the obesity and overweight rate among Iranian women: using urban health equity assessment and response tool. Int J Travel Med Glob Health. 2019;7(3):99-104. doi:10.15171/ijtmgh.2019.21.

\section{Introduction}

Overweight and obesity impose a substantial clinical burden on public health worldwide. Two hundred 5 million men and 297 million women in the world were suffering from obesity and overweight in 2008. ${ }^{1}$ The high prevalence of obesity, as an independent risk factor, is associated with an increase in obesity-related diseases, including cardiovascular diseases, hypertension, diabetes, stroke, and cancers. ${ }^{2,3}$ In a national survey in Iran in 2008, the prevalence of overweight, obesity, and severe obesity were reported to be $28.6 \%, 10.8 \%$, and $3.4 \%$, respectively. ${ }^{4}$ Iran, like other developing countries in the world, experiences rapid urbanization, and the metropolitan city of Tehran is no exception. ${ }^{5}$

In recent decades, with the participation of physicians, researchers, and health officials, attempts have been made to minimize health problems, including obesity and its related diseases. However, these efforts have not necessarily led to a reduction in healthcare inequalities. Efforts were fruitless, even in the provision of equitable access to health services. An excellent example of this is the health system in America. ${ }^{6}$ This fact has directed scientists towards the assessment and evaluation of non-clinical situations based on the social determinants of health, such as social, economic, political, and environmental conditions, that have a participatory role in the health problems of communities. ${ }^{7}$ Neighborhood health centers and their participation and performance have been beneficial and have led to lasting achievements, such as changes in the community made by community members toward promoting their health status. ${ }^{8,9}$

In order to achieve these objectives, the World Health Organization (WHO) has launched the first Urban Health Equity Assessment and Response Tool (Urban HEART)

Copyright $\odot 2019$ The Author(s). This is an open-access article distributed under the terms of the Creative Commons Attribution License (http:// creativecommons.org/licenses/by/4.0), which permits unrestricted use, distribution, and reproduction in any medium, provided the original work is properly cited. 
center in Kobe, Japan, to help evidence-based policymaking for the identification of inequities within and between cities in countries worldwide. ${ }^{10}$ This practical program not only provides a possibility to better understand community-based inequalities related to health causes, risks, and outcomes of local people with various socioeconomic categories, but also facilitates health strategies and interventions among citizens to reduce the prevalence of disorders and diseases. The WHO's Urban HEART follows six steps to achieve these goals: building an inclusive team, defining the local indicator set and benchmarks, assembling relevant and valid data, generating and developing evidence, evaluating and prioritizing health equity gaps and gradients, and identifying the best and most effective solutions. ${ }^{10-12}$

The Tehran municipality has implemented an intervention plan to reduce inequities and improve the indicators of Tehran Urban HEART with a community-based initiative approach and intersectoral collaboration at the neighborhood level. ${ }^{11,12}$ In the next step, community-based interventions were initiated following the outcomes from the Tehran Urban HEART. ${ }^{13}$

Unlike developed countries, the prevalence of obesity has been increasing in developing countries in recent decades and has become a pressing issue for the health of citizens. ${ }^{3}$ Therefore, out of the 79 indicators of the Tehran Urban HEART, the current study selected the overweight and obesity index for use in evaluating the results of communitybased interventions in 5 neighborhoods of Tehran, Iran. The aim was to investigate the effects of public participation on eliminating the problem of overweight or obesity among citizens.

\section{Methods}

Study Design and Participants

In 2013-2014, a pilot study was conducted to evaluate the effect of community-based interventions of Urban HEART for the prevention of overweight and obesity disorders among female populations in Tehran, the capital of Iran. Based on the available data in the municipality, the research plan was conducted in 103 out of 368 neighborhoods (27.98\%) in 22 districts of Tehran city. A high prevalence of obesity or overweight was seen, especially among women in the selected neighborhoods $(n=103)$, while other complications and diseases were prevalent in other neighborhoods $(n=265)$. Five districts were randomly selected to recruit the subjects in the central (no. 1), southern (no. 2), western (no. 3), northern (no. 4), and eastern (no. 5) areas of the province (Figure 1). Accordingly, the districts were selected in such a way that thoroughly covered the socioeconomic conditions of citizens in the entire city area. Cluster-sampling was applied in the pilot study. Census information was used as the sampling frame (The last census in Iran was performed in 2011). Based on census information, the sample was selected and the sampling data was prepared. One hundred and sixty-six women with overweight or obesity and at least 15 years of age with different levels of education (i.e., under diploma, high-school diploma, and associate degree or higher) and residential floor areas (i.e., $\leq 45 \mathrm{~m}^{2}, 46-75 \mathrm{~m}^{2}$, and $\geq 76 \mathrm{~m}^{2}$ ) entered the study and received

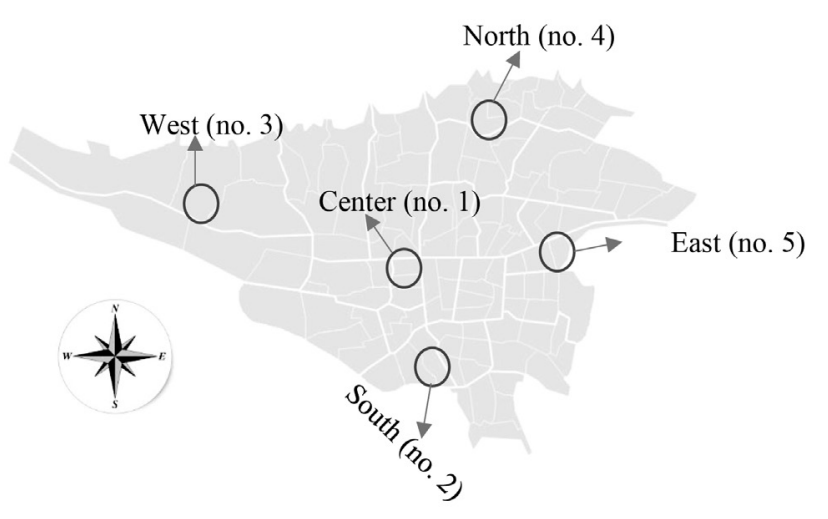

Figure 1. Map of Tehran With 5 Studied Regions.

the intervention after providing verbal and written consent. These people declared their readiness to participate in the project voluntarily after receiving face-to-face notification and through public awareness initiatives with brochures and pamphlets in health centers of the priority neighborhoods. The body mass index (BMI) of mothers was calculated by measuring the weight (in $\mathrm{kg}$ ) and dividing the result by the square of assessed height $\left(\right.$ in $\mathrm{m}^{2}$ ). According to the guidelines of the Centers for Disease Control and Prevention, a BMI of 25 to $29.9 \mathrm{~kg} / \mathrm{m}^{2}$ was considered as overweight, while a BMI greater than or equal to $30 \mathrm{~kg} / \mathrm{m}^{2}$ was defined as obese. ${ }^{14} \mathrm{~A}$ researcher-made questionnaire was also used to collect their socio-demographic data. The demographic questionnaire was validated by 15 experts of Tehran University of Medical Sciences.

\section{Inclusion and Exclusion Criteria}

The inclusion criteria in this study were female gender, age over 15 years old, and consent to participate. The exclusion criteria were limited to unwillingness to cooperate, having an underlying disease, and taking any medication.

\section{Implementation of Urban HEART Intervention}

The WHO developed the Urban HEART guidelines to acquire evidence of health inequalities and the influencing social factors in cities. The administrative and executive framework of this community-based intervention was based on the following provisions: (a) notifying the mayor and relevant authorities in municipal districts of the second round assessment results, (b) holding workshops and briefings for those involved in the project, $(c)$ formation of the neighborhood development committee, $(d)$ approval of the neighborhood priority or priorities for initiation of the intervention operations, $(e)$ formation of an intervention workgroup and holding executive workshops, $(f)$ developing the intervention program through individual and group interviews with local residents in the neighborhoods, $(g)$ intervention initiation, $(h)$ overseeing the process of the interventions, (i) the presentation of monthly and quarterly progress reports on the implementation of the program and its feedback, $(j)$ the use of intervention outcomes for monitoring and evaluating each neighborhood, $(k)$ documenting the 
outcomes in written form or as media, and $(l)$ participating in the Urban HEART festival in the districts and the city.

Before implementing the developed intervention activities (Table 1), the subjects were interviewed and asked about the severity and significance of their problem (overweight/obesity), the problem causes, analyzed measures, outcomes (success or failure), recommended strategies, and available resources. The women were selected from the studied neighborhoods in the 5 districts applied different interventions, including monthly educational programs, programs related to physical activities (such as walking, climbing, discounts on the use of sport clubs and gyms, etc), free monthly medical examinations, monthly individual and group nutrition counseling, and competitions and festivals. Interventions continued with careful planning in predetermined intervals for a duration of 4 months. Changes in the subjects' weight and BMI were recorded at monthly examinations. The internal consistency reliability of the checklist data was estimated using Cronbach's alpha coefficient. Cronbach's alpha for the constructed questionnaire was 0.902 , showing a high reliability. The checklist validity was also assessed through the content validity method using 10 experts in the areas of community health and medicine. The validity and reliability of the WHO's Urban HEART checklist was earlier demonstrated by Asadi-Lari et al. ${ }^{11}$

\section{Statistical Analysis}

The data obtained both before and after the intervention was statistically analyzed using the SPSS software package version 20.0 (SPSS Inc., Chicago, IL, USA) at a significance level of $P<$ 0.05 . All continuous values are expressed as mean \pm standard deviation (SD), and categorical variables are presented as frequencies or percentages. The one-sample KolmogorovSmirnov test was used to determine the normality of data distribution. The paired sample $t$ test was used to compare BMI results before and after the intervention. Linear regression analysis was also carried out to assess the predicting factors on intervention effectiveness (reduction amount of BMI). The studied parameters included age, education level, and average residential floor area.

\section{Results}

The outcomes of community-based interventions in the prevention of overweight and obesity were investigated. The distribution normality of data obtained in this study was evaluated using the one-sample Kolmogorov-Smirnov test. The 166 eligible subjects were women aged 15 years old or older with an overweight or obesity disorder and included 27 (16.3\%), 61 (36.8\%), 28 (36.7\%), 20 (12.0\%), and 30 (18.1\%) people from the first to the fifth districts, respectively. The mean age of the participants was $43.6 \pm 12.2$ years, with the minimum and maximum ages being 18 and 70 years, respectively. In total, 75 patients $(45.18 \%)$ and 91 patients $(54.82 \%)$ were found with overweight and obesity, respectively, in all of the 5 districts. Seventy-eight subjects (46.98\%) had a high school diploma, while 25 women (15.06\%) had an associate degree or higher (Table 2). Table 3 shows the prevalence of overweight and obesity among women from the target districts in Tehran after the implementation of the Urban HEART intervention in 2013-2014.

The average floor area of the subjects' residences was $77.2 \pm 34.3 \mathrm{~m}$, with a per capita population of 3 residents per house (falls within the group of 1-8 residents). The mean patient BMI was $30.3 \pm 2.7 \mathrm{~kg} / \mathrm{m}^{2}$ before the intervention and fell to $29.4 \pm 2.7 \mathrm{~kg} / \mathrm{m}^{2}$ after the intervention. According to the paired sample t-test, the difference between the BMI values before and after the intervention was statistically significant $(P<0.05)$. In addition, the difference between the BMI values of pre- and post-intervention was statistically significant in all but the fourth district. The $\mathrm{p}$-values of districts one through 5 were $0.003,<0.001,<0.001,0.4$, and $<0.001$, respectively.

Table 1. Summary of Developed Specific Interventions in the Urban HEART Framework

\begin{tabular}{|c|c|}
\hline Definiens & Details \\
\hline \multirow{8}{*}{ Activities } & Identification of eligible people within one week \\
\hline & Free monthly medical visits at health centers \\
\hline & Holding 4 training sessions to control weight at health centers during the intervention \\
\hline & Holding daily health stations \\
\hline & Providing free swimming pool tickets to the subjects \\
\hline & Holding monthly individual- and group-nutrition counseling \\
\hline & Organizing physical activity-based programs (such as hiking and climbing) \\
\hline & Holding sports competitions and food festivals \\
\hline \multirow{4}{*}{ Specific objectives } & Identification of qualified individuals \\
\hline & Training the subjects to prepare home-cooked, low-calorie, healthy foods \\
\hline & Monitoring the weight and height of subjects during interventional procedures \\
\hline & Increasing public awareness within 4 months \\
\hline \multirow{4}{*}{ Subject of the developed program } & Informing the citizens of target districts \\
\hline & Holding training classes and workshops \\
\hline & Offering individual- and group-counseling services \\
\hline & Organizing exercise programs \\
\hline Overall goal & Reaching a healthy weight \\
\hline
\end{tabular}


Table 2. Demographic Characteristics of Eligible Iranian Women Participating in the Urban HEART Intervention in Different Districts

\begin{tabular}{lc}
\hline Character & Value \\
\hline Population number ${ }^{\mathrm{a}}$, No., $(\%)$ & $27(16.3)$ \\
1 (the center) & $61(36.8)$ \\
2 (the south) & $28(36.7)$ \\
3 (the west) & $20(12.0)$ \\
4 (the north) & $30(18.1)$ \\
5 (the east) & \\
Age (y) & $43.6 \pm 12.2$ \\
Mean & 18 \\
Minimum & 70 \\
Maximum & \\
Education level & $63(37.96)$ \\
Under diploma & $78(46.98)$ \\
High school diploma & $25(15.06)$ \\
Associate degree or higher & $75(45.18)$ \\
Overweight rate [n, (\%)] & $91(54.82)$ \\
Obesity rate [n, (\%)] & \\
BMl (kg/m²) & $30.3 \pm 2.7$ \\
Before (the intervention) & $29.4 \pm 2.7$ \\
After (the intervention) & \\
\hline Total number of participants was 166. &
\end{tabular}

Table 3. Prevalence of Overweight and Obesity Among Women 15 Years Old or Older in Different Districts After the Urban HEART Intervention

\begin{tabular}{lcc}
\hline District & Prevalence of overweight (\%) & Prevalence of obesity (\%) ${ }^{\mathbf{a}}$ \\
\hline 1 (the center) & $23.3(13.9-32.6)$ & $28.6(18.2-39)$ \\
2 (the south) & $38.3(26.1-50.3)$ & $20.4(11.6-29.3)$ \\
3 (the west) & $34.2(22.7-45.6)$ & $17.8(9.6-26.1)$ \\
4 (the north) & $38.1(26.1-50.2)$ & $13.4(6.3-20.5)$ \\
5 (the east) & $34.6(23.1-46.1)$ & $19.9(11.2-28.6)$ \\
\hline
\end{tabular}

at a confidence interval of $95 \%$

For more effective control of BMI in the subjects, the predictive factors of overweight or obesity were identified by a regression model using the variables of age, education level, and residential floor area or per capita population at each home. The results shown in Table 4 indicate that the difference between BMI before and after the intervention for each unit increase in age increased by $0.015(P=0.003)$. Furthermore, the difference between BMI values pre- and post-intervention also increased by 0.038 with each increase in unit of residential floor area $(P<0.001)$. The difference between BMI values before and after intervention increased to 0.730 with education levels of high school diploma or higher $(P<0.001)$. Also, the regression association between the reduced BMI and each prediction factor, i.e. age $\left(R^{2}=0.040\right)$, residential floor area $\left(R^{2}=0.093\right)$, and education level $\left(R^{2}=\right.$ 0.179 ), was determined (Table 4 ). The order of effectiveness of predictors in reducing BMI values among Iranian women with obesity and overweight was education level $>$ residential floor area >age.

\section{Discussion}

This study addressed the results of community-based interventions in reducing the problems of overweight and obesity among Iranian women aged 15 years and older. Effective interventions must be implemented to control the prevalence of overweight and obesity, because these disorders are considered as independent risk factors for chronic diseases. ${ }^{2}$ The 2006 study of Kelishadi et $\mathrm{al}^{15}$ on the national data of obesity in Iran showed that health policymakers should deal seriously with unhealthy behaviors, especially physical inactivity, as the leading cause of obesity and seek essential remedies. Moreover, it was found that the incidence of overweight and obesity in Iran is more common among women than men. ${ }^{16}$

The results of the present study demonstrated the effectiveness of the Urban HEART intervention in reducing these risk factors among eligible women from the various districts who participated at the beginning of the Urban HEART project. Involvement and active participation of the community in health promotion can help detect the unmet needs of citizens and find existing gaps. Subsequently, suitable community-based initiatives will reduced inequities. ${ }^{17}$ Numerous studies have addressed the role of community participation in health promotion. Chen et $\mathrm{al}^{18}$ in China emphasized the role of public involvement in the development of a healthy environmental governance system. Chinese policymakers recently changed their policies in line with the full and active participation of environmental management. An advisory group was formed to encourage public participation, and it has been successful in increasing public awareness, improving environmental behavior, and, thus, facilitating public participation and involvement in environmental management.

Morrison et $\mathrm{al}^{19}$ introduced the role of community-based participation as an essential factor in interventions related to weight loss, which can help overcome wider social and environmental factors. In this type of study, community members act as researchers, and their priorities and vision will help shape future research. Focusing on community, two-way communications, shared responsibility, and relying on local empowerment will improve an environment where society members promote their abilities to cope with difficulties and to use regional capital to build healthy neighborhoods. People will learn what to do and how to do the right things. ${ }^{7}$ The results showed that although various factors have different

Table 4. Regression Analysis of Predictors Based on the Difference Between BMI Values of Pre- and Post-interventions

\begin{tabular}{|c|c|c|c|c|c|}
\hline \multirow{2}{*}{ Predictors } & \multirow{2}{*}{ B coefficient } & \multirow{2}{*}{$\mathbf{R}^{2}$} & \multirow{2}{*}{$P$ Value } & \multicolumn{2}{|c|}{ Confidence interval of $95 \%$} \\
\hline & & & & Minimum & Maximum \\
\hline Constant value & -1.800 & & 0.015 & -3.350 & -0.360 \\
\hline Residential floor area & 0.038 & 0.093 & $<0.001$ & 0.023 & 0.053 \\
\hline Education level $^{a}$ & 0.730 & 0.179 & $<0.001$ & 0.340 & 1.110 \\
\hline Age & 0.015 & 0.040 & 0.003 & 0.005 & 0.025 \\
\hline
\end{tabular}

${ }^{a}$ Diploma failed vs. high school diploma or higher. 
effects on health, they join and act together in a society. Participation by researchers and community on how to use the acquired knowledge has been significantly helpful. ${ }^{20}$

The results of this study indicated that the interventional effects of 2 factors, higher education level and greater residential floor area, were significantly stronger than the other element "age". In the research conducted by Conklin et $\mathrm{al}^{21}$ on British citizens, the relationship between obese and low financial status was approved. According to the findings of Salonen, low education level and social class were associated with increased BMI. ${ }^{22}$ Accordingly, more attention should be given the optimal management of resources under conditions of insufficient funding and fewer facilities for people with a lower socioeconomic status.

The most important strength of this research was its use of accurate methods to identify priorities based on local capital and attitudes, feasibility, acceptability, cultural context, and local knowledge.

In this research, the type of intervention was selected based on the results of interviews with community members, which led to the allocation of limited health resources to priority measures in the neighborhoods based on their particular economic, social, and cultural status. The results were released in academic circles and to the public to increase public awareness. These activities and actions are continuing in neighborhoods located in different districts of Tehran.

The current study had some limitations, such as the small number of participants in the early stages of the interventions in different districts. This could be explained by the inexperience of the responsible authorities in implementing such interventions. However, the data suggests that interventions with a greater number of participants (e.g., more than 200 people in each neighborhood) should be continued.

\section{Conclusion}

This study represents the successful collaborative role of the community in improving the health status of citizens by reducing the prevalence rates of overweight and obesity. As the health of citizens is a crucial policy in developing countries, it is suggested that similar Urban HEART interventions be designed and implemented in other Iranian cities. Creating an up-to-date database containing the health and medical information of citizens or using existing state-of-the-art systems such as electronic health records is recommended to more easily and quickly evaluate the citizens' health status from various aspects. Accordingly, the incidence of other epidemics and pandemic outbreaks at the national level can be identified and prevented using the Urban HEART program. Socioeconomic data can be applied as a robust prediction tool to adopt the best strategies for promoting public health in society. Meanwhile, future studies should direct more attention to designing interventions that assess the impact of education level and residential floor area on BMI changes. Policy-makers and health managers would be able to prioritize the most active micro- and macro-health policies for controlling risk factors and enhancing the health status of the community.

\section{Research Highlights}

\section{What Is Already Known?}

Urban HEART is an efficient decision-support guideline for identifying health inequities and presents practical actions to decrease them in communities.

\section{What This Study Adds?}

The progress of Urban HEART interventions effectively allows the control of obesity and overweight rates among women of reproductive age in the Tehran metropolis with the ability to identify predictive factors of the prevalence of these health disorders.

\section{Conflict of Interest Disclosures}

The authors declare that they have no competing interests.

\section{Authors' Contribution}

FR and FK designed the study, collected and analyzed the data, and wrote the article. LK revised and drafted the study. All the authors interpreted the data and approved the final version to be published.

\section{Ethical Approval}

Informed consent was obtained from all individual participants included in the study. All procedures involving human participants were performed following the guidelines laid down in the Declaration of Helsinki and were approved by the Health Department of Tehran Municipality.

\section{Funding/Support}

None received.

\section{Acknowledgments}

This study was part of the results of the plan entitled "Inequity Assessment, Intervention Design, and Identification of Indicators to Reduce Inequities in Tehran City with a Community-Based Approach". The authors would like to thank the participating trained citizens, nutritionists, psychologists, and health department's personnel in Tehran Municipality as well as the participating health offices in various districts of Tehran.

\section{References}

1. Finucane MM, Stevens GA, Cowan MJ, et al. National, regional, and global trends in body-mass index since 1980: systematic analysis of health examination surveys and epidemiological studies with 960 country-years and 9.1 million participants. Lancet. 2011;377(9765):557-567. doi:10.1016/s0140-6736(10)62037-5.

2. Ning $X$, Zhan $C$, Yang $Y$, et al. Secular trends in prevalence of overweight and obesity among adults in rural Tianjin, China from 1991 to 2011: a population-based study. PLoS One. 2014;9(12):e116019. doi:10.1371/journal.pone.0116019.

3. $\mathrm{Ng} \mathrm{M}$, Fleming $\mathrm{T}$, Robinson $\mathrm{M}$, et al. Global, regional, and national prevalence of overweight and obesity in children and adults during 1980-2013: a systematic analysis for the Global Burden of Disease Study 2013. Lancet. 2014;384(9945):766-781. doi:10.1016/ s0140-6736(14)60460-8.

4. Kelishadi R, Alikhani S, Delavari A, Alaedini F, Safaie A, Hojatzadeh E. Obesity and associated lifestyle behaviours in Iran: 
findings from the First National Non-communicable Disease Risk Factor Surveillance Survey. Public Health Nutr. 2008;11(3):246251. doi:10.1017/s1368980007000262.

5. Ghassemi H, Harrison G, Mohammad K. An accelerated nutrition transition in Iran. Public Health Nutr. 2002;5(1a):149-155. doi:10.1079/phn2001287.

6. Siddiqi A, Hertzman C. Towards an epidemiological understanding of the effects of long-term institutional changes on population health: a case study of Canada versus the USA. Soc Sci Med. 2007;64(3):589-603. doi:10.1016/j.socscimed.2006.09.034.

7. Horowitz CR, Robinson M, Seifer S. Community-based participatory research from the margin to the mainstream: are researchers prepared? Circulation. 2009;119(19):2633-2642. doi:10.1161/circulationaha.107.729863.

8. Cargo M, Mercer SL. The value and challenges of participatory research: strengthening its practice. Annu Rev Public Health. 2008;29:325-350. doi:10.1146/annurev. publhealth.29.091307.083824.

9. Mensah GA. Eliminating disparities in cardiovascular health: six strategic imperatives and a framework for action. Circulation. 2005;111(10):1332-1336. doi:10.1161/01. cir.0000158134.24860.91.

10. World Health Organization (WHO). WHO Centre for Health Development. Urban HEART: Urban Health Equity Assessment and Response Tool-manual. Kobe Japan, 2010. http://www.who. int/kobe_centre/publications/urban_heart_manual.pdf.

11. Asadi-Lari M, Vaez-Mahdavi MR, Faghihzadeh S, et al. Responseoriented measuring inequalities in Tehran: second round of UrbanHealth Equity Assessment and Response Tool (Urban HEART-2), concepts and framework. Med J Islam Repub Iran. 2013;27(4):236-248.

12. Allahverdipoor $\mathrm{H}$, Behdjat $\mathrm{H}$, Tajaddini $\mathrm{N}$, Vahidi $\mathrm{RG}$, Jabbari $\mathrm{H}$. Report on documentation and evaluation of Urban HEART pilot in Tehran, Islamic Republic of Iran. Tabriz: National Public Health Management Centre, Tabriz Univ Med Sci; 2013.

13. Vaez-Mahdavi MR, Asadi-Lari M, Malekafzali H. Urban HEART Tehran experience: Round II results. Tehran: Municipality of
Tehran; 2013.

14. Centers for Disease Control and Prevention (CDC). Defining Adult Overweight and Obesity. CDC; 2015. http://www.cdc.gov/obesity/ adult/defining.html.

15. Kelishadi R, Alikhani S, Delavari A, Alaedini F, Safaie A, Hojatzadeh E. Obesity and associated lifestyle behaviours in Iran: findings from the First National Non-communicable Disease Risk Factor Surveillance Survey. Public Health Nutr. 2008;11(3):246251. doi:10.1017/s1368980007000262.

16. Ayatollahi SM, Ghoreshizadeh Z. Prevalence of obesity and overweight among adults in Iran. Obes Rev. 2010;11(5):335-337. doi:10.1111/j.1467-789X.2010.00725.x.

17. Fradgley EA, Paul CL, Bryant J, Roos IA, Henskens FA, Paul DJ. Consumer participation in quality improvements for chronic disease care: development and evaluation of an interactive patient-centered survey to identify preferred service initiatives. J Med Internet Res. 2014;16(12):e292. doi:10.2196/jmir.3545.

18. Chen M, Qian X, Zhang L. Public participation in environmental management in China: status quo and mode innovation. Environ Manage. 2015;55(3):523-535. doi:10.1007/s00267-014-0428-2.

19. Morrison Z, Douglas A, Bhopal R, Sheikh A. Understanding experiences of participating in a weight loss lifestyle intervention trial: a qualitative evaluation of South Asians at high risk of diabetes. BMJ Open. 2014;4(6):e004736. doi:10.1136/ bmjopen-2013-004736.

20. Satcher D, Higginbotham EJ. The public health approach to eliminating disparities in health. Am J Public Health. 2008;98(3):400-403. doi:10.2105/ajph.2007.123919.

21. Conklin AI, Forouhi NG, Suhrcke M, Surtees P, Wareham NJ, Monsivais P. Socioeconomic status, financial hardship and measured obesity in older adults: a cross-sectional study of the EPIC-Norfolk cohort. BMC Public Health. 2013;13:1039. doi:10.1186/1471-2458-13-1039.

22. Salonen MK, Kajantie E, Osmond C, et al. Role of socioeconomic indicators on development of obesity from a life course perspective. J Environ Public Health. 2009;2009:625168. doi:10.1155/2009/625168. 